\title{
High-dose Intravenous Immunoglobulin Treatment Increases Regulatory T Cells in Patients with Eosinophilic Granulomatosis with Polyangiitis
}

\author{
NAOMI TSURIKISAWA, HIROSHI SAITO, CHIYAKO OSHIKATA, TAKAHIRO TSUBURAI, and KAZUO AKIYAMA
}

\begin{abstract}
Objective. We studied the effects of intravenous immunoglobulin (IVIG) treatment on clinical symptoms and regulatory $\mathrm{T}$ (Treg) cell frequency in patients with eosinophilic granulomatosis with polyangiitis (EGPA).

Methods. Twenty-two EGPA patients with severe mononeuritis multiplex or cardiac dysfunction received IVIG therapy combined with conventional therapy (corticosteroid, immunosuppressants, or both). As a control, 24 EGPA patients without severe vasculitic symptoms were treated with conventional therapy. Before, during, and after treatment, we determined percentages of Treg cells and other relevant cells in patients' peripheral blood.

Results. The frequency of CD25+ among CD4+ T cells was lower at onset in the study group than in controls but increased significantly after IVIG treatment, relative to controls. The frequency of CD25+ among CD4+ $\mathrm{T}$ cells correlated with the frequency of FOXP3+ among CD4+ T cells and interleukin 10 produced by $\mathrm{CD} 25+\mathrm{CD} 4+\mathrm{T}$ cells.

Conclusion. The increase in Treg cells seen with the combination of IVIG and conventional therapy may promote remission in EGPA. (First Release April 1 2012; J Rheumatol 2012;39:1019-25; doi:10.3899/ jrheum.110981)
\end{abstract}

Key Indexing Terms:

EOSINOPHILIC GRANULOMATOSIS WITH POLYANGIITIS REGULATORY T CELLS CHURG-STRAUSS SYNDROME

INTRAVENOUS IMMUNOGLOBULIN

Eosinophilic granulomatosis with polyangiitis (EGPA; also known as Churg-Strauss syndrome) is a rare disease characterized by allergic granulomatosis and necrotizing vasculitis following peripheral and tissue eosinophilia ${ }^{1}$.

The mortality and prognosis of EGPA are related to disease severity, as assessed by 5 -factor scores ${ }^{2}$. In some patients with EGPA, mononeuritis multiplex, heart failure, or antineutrophil cytoplasmic antibody (ANCA)-associated systemic vasculitis do not respond to the combination therapy of corticosteroids (CS) and cyclophosphamide $(\mathrm{CYC})^{3,4}$. We reported ${ }^{5}$ that intravenous immunoglobulin (IVIG) therapy improved severe mononeuritis multiplex or heart failure in patients with EGPA who did not respond to the combination therapy.

Regulatory $\mathrm{T}$ (Treg) cells play a key role in balancing immune responses and maintaining peripheral tolerance ${ }^{6}$.

From the Clinical Research Center for Allergy and Rheumatology,

National Hospital Organization, Sagamihara National Hospital,

Kanagawa, Japan.

N. Tsurikisawa, MD; H. Saito, PhD; C. Oshikata, MD; T. Tsuburai, MD; K. Akiyama, MD, Clinical Research Center for Allergy and Rheumatology, National Hospital Organization, Sagamihara National Hospital.

Address correspondence to Dr. N. Tsurikisawa, Clinical Research Center for Allergy and Rheumatology, National Hospital Organization,

Sagamihara National Hospital, 18-1 Sakuradai, Minami-ku,

Sagamihara, Kanagawa, Japan 252-0392.

E-mail: n-tsurikisawa@sagamihara-hosp.gr.jp

Full Release Article. For details see Reprints/Permissions at jrheum.org

Accepted for publication January 17, 2012.
We reported that, at the onset of disease, patients with EGPA had a lower frequency of Treg cells than patients with general asthma and the frequency of Treg cells increased at remission ${ }^{7}$.

IVIG treatment has shown clinical efficacy ${ }^{8}$ and regulates activation of Treg cells in autoimmune and immunemediated inflammatory diseases ${ }^{9}$. Mechanisms implicated in IVIG modulation of Treg function include activation and induction of Treg cells by the Fc or F(ab') ${ }_{2}$ domain of IVIG and enhancement of Treg function by increasing expression of FOXP3, transforming growth factor $\beta$, interleukin 10 (IL-10), and cytotoxic T lymphocyte antigen $4^{9,10,11,12,13}$.

We examined whether patients with EGPA who were treated with IVIG in combination with conventional therapy had modified clinical symptoms, modified immune measurements, and a reduced maintenance dose of CS.

\section{MATERIALS AND METHODS}

Patients. Between March 1985 and February 2007, 46 patients were recruited at the onset of EGPA, diagnosed by the classification criteria of the American College of Rheumatology ${ }^{14}$. All patients treated with IVIG had severe neuropathy $[<3$ on the manual muscle test (MMT) using the Medical Research Council scale (0 to 5)] or cardiac involvement, including severe heart failure or myocarditis or pericarditis, which did not improve after at least 1 month of treatment with conventional therapy (CS, immunosuppressants, or both). Control patients with EGPA who received treatment but no IVIG did not have severe impediments such as neuropathy $(<3$ on the MMT) or severe cardiac dysfunction after treatment with CS, immunosuppressants, or both. 
Study design. A diagram of the study design is given in Figure 1. Before treatment, all patients treated with IVIG (Venilon, Teijin, Tokyo, Japan; 400 $\mathrm{mg} / \mathrm{kg}$ daily for 5 days), received CS [about $1 \mathrm{mg} / \mathrm{kg} /$ day prednisolone (PSL) as an initial dose] and 21 of the 22 patients were also treated with CYC (pulse or oral) for a median time of 3.0 months (range 1.0-215.0 mo). Treatments were between July 1999 and September 2007. Some patients with difficult mononeuritis multiplex or heart failure were given additional IVIG treatments between 2 to 12 months after beginning therapy. We measured the percentage of Treg cells in the peripheral blood of patients treated with IVIG at $0,3,6,12$, and 24 months after the last IVIG dose in patients given IVIG, and at 4, 14, 17, 20, 26, and 38 months after onset in the controls. Treg cells were defined as $\mathrm{CD} 25+\mathrm{CD} 4+\mathrm{T}$ cells dominantly producing IL-10 or FOXP3+CD4+ T cells (Figure 1). We examined the dose of CS used for patients in remission 2 years after the last IVIG treatment and at about 38 months from onset in controls. Remission was defined as the absence of any clinical signs or symptoms of active vasculitis for at least 6 months. The ethics committee of our hospital approved the study and we obtained informed consent from each patient.

Immunological analysis. The frequencies of CD25+ among CD4+ T cells and FOXP3+ among CD4+ $\mathrm{T}$ cells were determined as described by Abdulahad, et al $^{15}$ and those of IL-10 produced by CD25+CD4+ T cells as described by Picker, et $a l^{16}$.

\section{RESULTS}

There were no significant differences in the ages at onset of patients with asthma, EGPA, or atopy, or of asthma severity between the study group and controls. Total white blood cell counts (WBC), eosinophil counts, and the number of patients positive for myeloperoxidase-specific ANCA did not differ significantly between the 2 groups (Table 1 ).
Organ involvement in the 2 patient populations is given in Table 2. All patients, whether treated with IVIG or not, had asthma and multiple polyneuropathy. However, the minimum MMT score was lower in patients given IVIG than in the control group $(\mathrm{p}<0.01)$. Myocardial and gastrointestinal (GI) tract problems were more common in the group treated with IVIG than in the group not given IVIG $(\mathrm{p}<$ $0.05)$. There were no significant differences between the groups in any other organ involvement excluding asthma and sinusitis, and the cumulative number of organ problems did not differ significantly between the 2 groups. However, the 5-factor scores in patients treated with IVIG were higher than in those not given IVIG $(\mathrm{p}<0.01)$. Renal involvement included proteinuria, eosinophils in urine, glomerular nephritis, nephrosis, or renal dysfunction. There were no significant differences between the 2 groups in proteinuria (IVIG-treated group vs control group: $40.9 \%$ vs $29.4 \%$, respectively), eosinophils in urine (36.4\% vs $35.3 \%)$, and nephritis or nephrosis $(9.1 \%$ vs $11.8 \%)$. The initial dose of CS or the percentage of patients who received CS pulse or immunosuppressant did not differ significantly between the 2 groups (Table 3 ).

Patients treated with IVIG showed involvement in the GI tract, lung, skin, nose, ear, and renal system with CS, immunosuppressants, or both before receiving IVIG. In contrast, mononeuritis multiplex or heart failure in patients treated with IVIG did not improve with the conventional

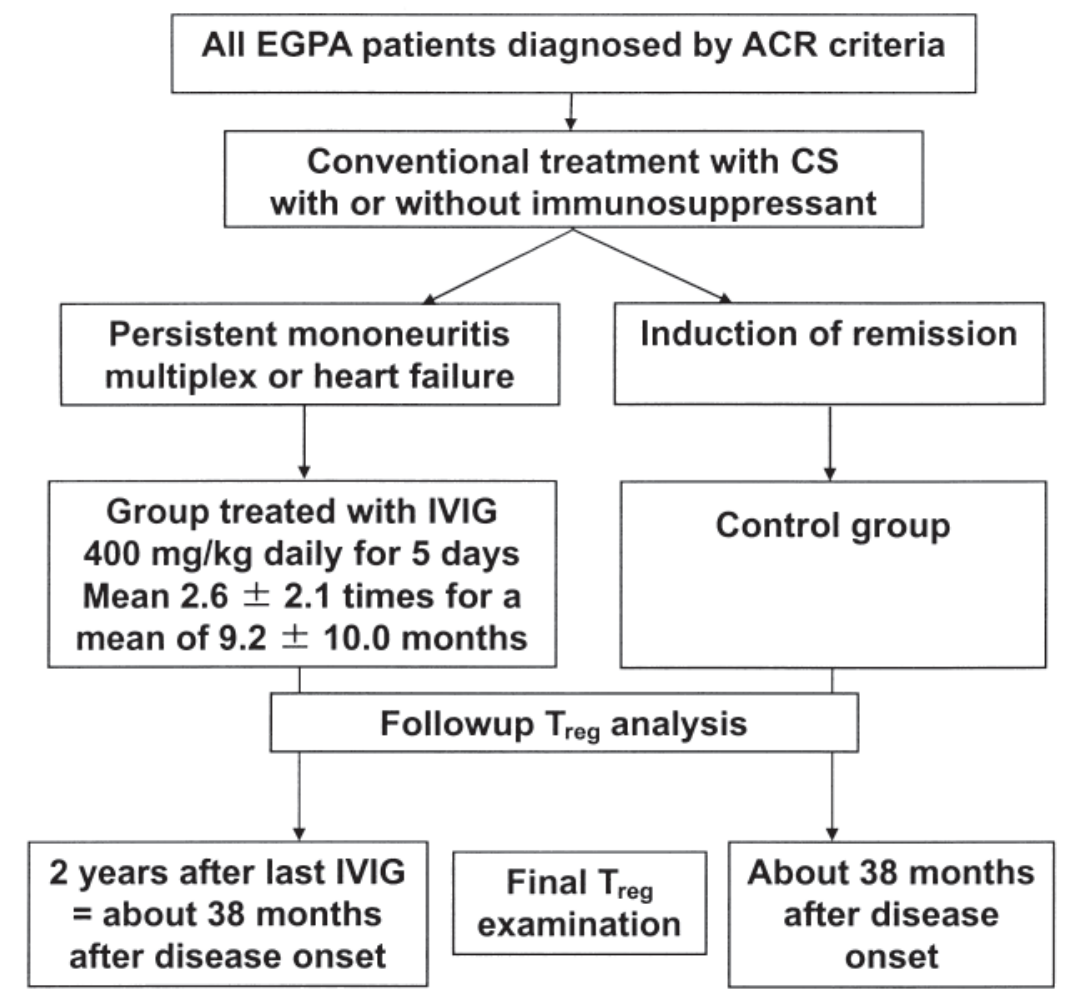

Figure 1. Study protocol. EGPA: eosinophilic granulomatosis with polyangiitis; ACR: American College of Rheumatology; CS: corticosteroids; IVIG: intravenous immunoglobulin; Treg: regulatory $\mathrm{T}$ cell. 
Table 1. Patient characteristics.

\begin{tabular}{lccc}
\hline Characteristic & $\begin{array}{c}\text { EGPA Patients } \\
\text { with IVIG, } \\
\mathrm{n}=22\end{array}$ & $\begin{array}{c}\text { EGPA Patients } \\
\text { without IVIG, } \\
\mathrm{n}=24\end{array}$ & $\mathrm{p}$ \\
\hline Age, yrs, mean \pm SD & $65.3 \pm 12.7$ & $58.4 \pm 15.0$ & $\mathrm{NS}^{\dagger}$ \\
Sex (M/F) & $5 / 17$ & $7 / 17$ & $\mathrm{NS}^{*}$ \\
Age at onset of asthma, yrs, mean \pm SD & $47.9 \pm 14.6$ & $41.3 \pm 16.9$ & $\mathrm{NS}^{\dagger}$ \\
Age at onset of EGPA, yrs, mean \pm SD & $55.8 \pm 14.8$ & $49.8 \pm 15.1$ & $\mathrm{NS}^{\dagger}$ \\
Type: atopy/nonatopy & $5 / 17$ & $11 / 13$ & $\mathrm{NS}^{*}$ \\
Step 1/2/3/4 at severity of asthma & $1 / 0 / 4 / 17$ & $2 / 4 / 3 / 15$ & $\mathrm{NS}^{*}$ \\
At onset EGPA & & & \\
WBC (cells/ $\mu 1)$, mean \pm SD & $15,794.1 \pm 6512.9$ & $12,793.9 \pm 5320.9$ & $\mathrm{NS}^{\dagger}$ \\
Blood eosinophils (cells/ $\mu$ l), mean \pm SD & $9305.6 \pm 6025.8$ & $6014.6 \pm 5096.4$ & $\mathrm{NS}^{\dagger}$ \\
MPO-ANCA (\%) & 27.3 & 17.4 & $\mathrm{NS}^{*}$ \\
PR3-ANCA (\%) & 0 & 0 & $\mathrm{NS}^{*}$ \\
CD25+ among CD4+ T cells $(\%)$, mean \pm SD & $33.9 \pm 10.2, \mathrm{n}=17$ & $42.6 \pm 16.6, \mathrm{n}=14$ & $0.02^{\dagger \dagger}$ \\
FOXP3+ among CD4+ T cells $(\%)$, mean \pm SD & $1.6 \pm 0.7, \mathrm{n}=6$ & $2.4 \pm 0.8, \mathrm{n}=9$ & $0.05^{\dagger \dagger}$ \\
IL-10 produced by CD25+ CD4+ T cells $(\%)$, & $0.5 \pm 1.3, \mathrm{n}=6$ & $0.0 \pm 0.0, \mathrm{n}=9$ & $\mathrm{NS}^{\dagger \dagger}$ \\
mean \pm SD & & & \\
\hline
\end{tabular}

Values of $\mathrm{p}<0.05$ were considered significant. ${ }^{\dagger} 2$-way ANOVA with repeated measures among 2 groups. $\uparrow$ Statistical comparisons carried out using the Mann-Whitney U test among 2 groups. * Chi-square testing revealed no significant differences in the frequencies of 2 groups. EGPA: eosinophilic granulomatosis with polyangiitis; IVIG: intravenous immunoglobulin; NS: not significant; WBC: white blood cells; MPO-ANCA: myeloperoxidase-specific antineutrophil cytoplasmic antibodies; PR3: proteinase 3 .

Table 2. Organ involvement at onset $(\%)$.

\begin{tabular}{lccc}
\hline & $\begin{array}{c}\text { EGPA Patients } \\
\text { with IVIG, } \\
\mathrm{n}=22\end{array}$ & $\begin{array}{c}\text { EGPA Patients } \\
\text { without IVIG, } \\
\mathrm{n}=24\end{array}$ & $\mathrm{p}$ \\
\hline Asthma & 100 & 100 & $\mathrm{NS}^{*}$ \\
Paranasal sinusitis & 100 & 87 & $\mathrm{NS}^{*}$ \\
Multiple polyneuropathy & 100 & 100 & $\mathrm{NS}^{*}$ \\
Minimum MMT score, mean $\pm \mathrm{SD}$ & $2.6 \pm 1.0$ & $3.9 \pm 0.8$ & $\mathrm{p}<0.01^{\dagger}$ \\
Pulmonary infiltrates & 76.2 & 81.8 & $\mathrm{NS}^{*}$ \\
Myocardial involvement & 78.9 & 47.8 & $0.04^{*}$ \\
Gastrointestinal tract & 90 & 58.3 & $0.02^{*}$ \\
Liver, gall bladder, pancreas & 25 & 8.7 & $\mathrm{NS}^{*}$ \\
Renal involvement** & 54.5 & 43.8 & $\mathrm{NS}^{*}$ \\
Proteinuria & 40.9 & 29.4 & $\mathrm{NS}^{*}$ \\
Eosinophils in urine & 36.4 & 35.3 & $\mathrm{NS}^{*}$ \\
Nephritis or nephrosis & 9.1 & 11.8 & $\mathrm{NS}^{*}$ \\
Skin involvement & 66.7 & 61.9 & $\mathrm{NS}^{*}$ \\
Arthritis & 31.8 & 37.5 & $\mathrm{NS}^{*}$ \\
Myalgia & 17.6 & 20.8 & $\mathrm{NS}^{*}$ \\
Central nervous system involvement & 13.6 & 25 & $\mathrm{NS}^{*}$ \\
Extravascular eosinophils (pathology) & 90.9 & 83.3 & $\mathrm{NS}^{*}$ \\
ACR 4 of the 6,5 of the 6,6 of the 6 & $1 / 6 / 15$ & $3 / 8 / 13$ & $\mathrm{NS}^{*}$ \\
Cumulative organ involvement***, $\mathrm{n}$, mean $\pm \mathrm{SD}$ & $5.2 \pm 1.9$ & $4.5 \pm 1.7$ & $\mathrm{NS}^{\dagger}$ \\
5-factor score & $2.1 \pm 0.9$ & $1.4 \pm 0.8$ & $\mathrm{p}<0.01^{\dagger}$ \\
\hline
\end{tabular}

Values of $\mathrm{p}<0.05$ considered statistically significant. ${ }^{\dagger} 2$-way ANOVA with repeated measures among 2 groups. * Chi-square testing revealed no significant differences in frequencies of the 2 groups. ** Renal involvement including proteinuria, eosinophils in urine, glomerular nephritis, nephrosis, or renal dysfunction. *** Cumulative organ involvement excluding asthma and sinusitis. EGPA: eosinophilic granulomatosis with polyangiitis; IVIG: intravenous immunoglobulin; NS: not significant; MMT: manual muscle test; ACR: American College of Rheumatology.

therapy. For patients with EGPA who were treated with IVIG, the median time from onset to the initial IVIG treatment was 3.5 months (range 1.0-216.0). Some patients needed several IVIG treatments to achieve remission. For those patients, the mean number of IVIG treatments was 2.6 \pm 2.1 (mean $\pm \mathrm{SD}$ ). Minimum MMT score at onset in 


\begin{tabular}{|c|c|c|c|}
\hline & $\begin{array}{l}\text { EGPA Patients } \\
\text { with IVIG, } \\
\text { n }=22\end{array}$ & $\begin{array}{c}\text { EGPA Patients } \\
\text { without IVIG, } \\
n=24\end{array}$ & $\mathrm{p}$ \\
\hline PSL as initial dose, $\mathrm{mg} / \mathrm{kg}$ & $0.96 \pm 0.2$ & $0.8 \pm 0.2$ & $\mathrm{NS}^{\dagger}$ \\
\hline Patients given steroid pulse (\%) & 68.2 & 54.2 & NS* \\
\hline Patients taking immunosuppressant $(\%)$ & 95.5 & 79.2 & NS* \\
\hline CYC/AZA/CSA & $21 / 0 / 0$ & $16 / 1 / 2$ & NS* \\
\hline Median time from onset to initial IVIG treatment, mo (range) & $3.5(1.0-216.0)$ & & \\
\hline IVIG, no. courses, mean \pm SD & $2.6 \pm 2.1$ & 0 & $\mathrm{p}<0.01^{\dagger}$ \\
\hline Mean time from first IVIG to last treatment, mo & $9.2 \pm 10.0$ & & \\
\hline PSL at 2 yrs after last IVIG or about 38 mo from onset, mg & $5.5 \pm 2.4$ & $7.7 \pm 2.9$ & $\mathrm{p}<0.01^{\dagger}$ \\
\hline
\end{tabular}

Values of $\mathrm{p}<0.05$ considered statistically significant. ${ }^{\dagger} 2$-way ANOVA with repeated measures among 2 groups. $*$ Chi-square testing revealed no significant differences in the frequencies of 2 groups. EGPA: eosinophilic granulomatosis with polyangiitis; NS: not significant; PSL: prednisolone; CYC: cyclophosphamide; AZA: azathioprine; CSA: cyclosporine; IVIG: intravenous immunoglobulin.

patients treated with IVIG did not significantly improve after CS, immunosuppressants, or both, from $2.6 \pm 1.0$ at onset to $2.8 \pm 9.8$ after the conventional therapy. The minimum MMT score after the last IVIG dose increased significantly to $4.3 \pm 0.5$ more than those at onset or after the conventional therapy $(\mathrm{p}<0.01)$. The sensory nerve symptoms of 16 of 22 patients $(72.7 \%$ ) had improved. Eight patients with severe cardiac dysfunction in the group treated with IVIG showed an increased ejection fraction, from $47.0 \% \pm$ $9.9 \%$ before IVIG to $65.3 \% \pm 11.4 \%$ after the last IVIG treatment $(\mathrm{p}<0.01)$. The ejection fraction of 6 of 8 patients (75\%) improved and normalized. Relevant to clinical management of these patients, the amount of PSL at 2 years after the last IVIG or at about 38 months from onset of EGPA was lower in patients treated with IVIG than in those without IVIG ( $p<0.01$; Table 3 ). The number of cumulative organ involvements in remission in the 2 groups decreased significantly from before treatments (Table 4).

In patients treated with IVIG, the percentage of CD25+ among CD4+ T cells increased significantly at 1 week after initial IVIG treatment $(\mathrm{p}<0.05)$ and increased further by 1 month ( $p<0.01$ compared to before IVIG treatment began, data not shown). The increase in Treg cells preceded disease remission. In the group treated with IVIG, the percentages of CD25+ among CD4+ T cells and FOXP3+ among CD4+ $\mathrm{T}$ cells at onset were significantly lower than in the control group (Table 1). However, at 3, 6, 12, and 24 months after the last IVIG dose, the percentage of these cells increased in the treated group (Figure 2).

For patients with EGPA who were treated with IVIG, the mean time from the first to last IVIG dose was $9.2 \pm 10.0$ months (Table 3) and the change in percentage of CD25+

Table 4. Treg cells at remission of eosinophilic granulomatosis with polyangiitis (EGPA) after treatment with corticosteroids and/or immunosuppressants, with or without intravenous immunoglobulin (IVIG).

\begin{tabular}{lccc}
\hline & $\begin{array}{c}\text { EGPA Patients } \\
\text { with IVIG, } \\
\mathrm{n}=22\end{array}$ & $\begin{array}{c}\text { EGPA Patients } \\
\text { without IVIG, } \\
\mathrm{n}=24\end{array}$ & $\mathrm{p}$ \\
\hline Factor & $9.4 \pm 5.6$ & $8.3 \pm 7.5$ & $\mathrm{NS}^{\dagger}$ \\
Period of assay from onset, yrs, mean \pm SD & $6673.5 \pm 1799.4^{\#}$ & $7702.4 \pm 2566.3^{\#}$ & $\mathrm{NS}^{\dagger}$ \\
WBC (cells $/ \mu 1$ ), mean \pm SD & $185.9 \pm 123.0^{\#}$ & $265.9 \pm 210.6^{\#}$ & $\mathrm{NS}^{\dagger}$ \\
Blood eosinophils (cells $/ \mu 1$ ) & $65.7 \pm 9.1^{\#}$ & $59.9 \pm 8.9^{\#}$ & $0.04^{\dagger \dagger}$ \\
CD25+ among CD4+ T cells (\%), mean \pm SD & $4.5 \pm 4.0^{\#}$ & $2.3 \pm 3.1^{\#}$ & $\mathrm{NS}^{\dagger \dagger}$ \\
IL-10 produced by CD25+CD4+ T cells (\%) & $5.4 \pm 7.2^{\#}$ & $4.1 \pm 1.8^{\#}$ & $0.04^{\dagger \dagger}$ \\
FOXP3+ among CD4+ T cells (\%) & $4.8 \pm 2.3$ & $6.4 \pm 2.4$ & $0.03^{\dagger}$ \\
Treatment at assay in remission state & 31.8 & 33.3 & $\mathrm{NS}^{*}$ \\
PSL, mg & $1.2 \pm 0.8$ & $1.0 \pm 0.8$ & $\mathrm{NS}^{\dagger}$ \\
Patients taking immunosuppressant $(\%)$ & & & \\
Cumulative organ involvement**, $\mathrm{n}$, mean $\pm \mathrm{SD}$ & & & \\
\hline
\end{tabular}

Values of $\mathrm{p}<0.05$ were considered statistically significant. ${ }^{\dagger}$ 2-way ANOVA with repeated measures among 2 groups. ${ }^{\dagger \dagger}$ Statistical comparisons carried out using the Mann-Whitney U test among 2 groups. ${ }^{\#} \mathrm{p}<0.01$ with statistical comparisons by paired $\mathrm{T}$ test in the same patients at onset and at remission. * Chi-square testing revealed no significant differences in the frequencies of 2 groups. ** Cumulative organ involvement excluding asthma and sinusitis. NS: not significant; WBC: white blood cells; PSL: prednisolone. 
A

IVIG treated group
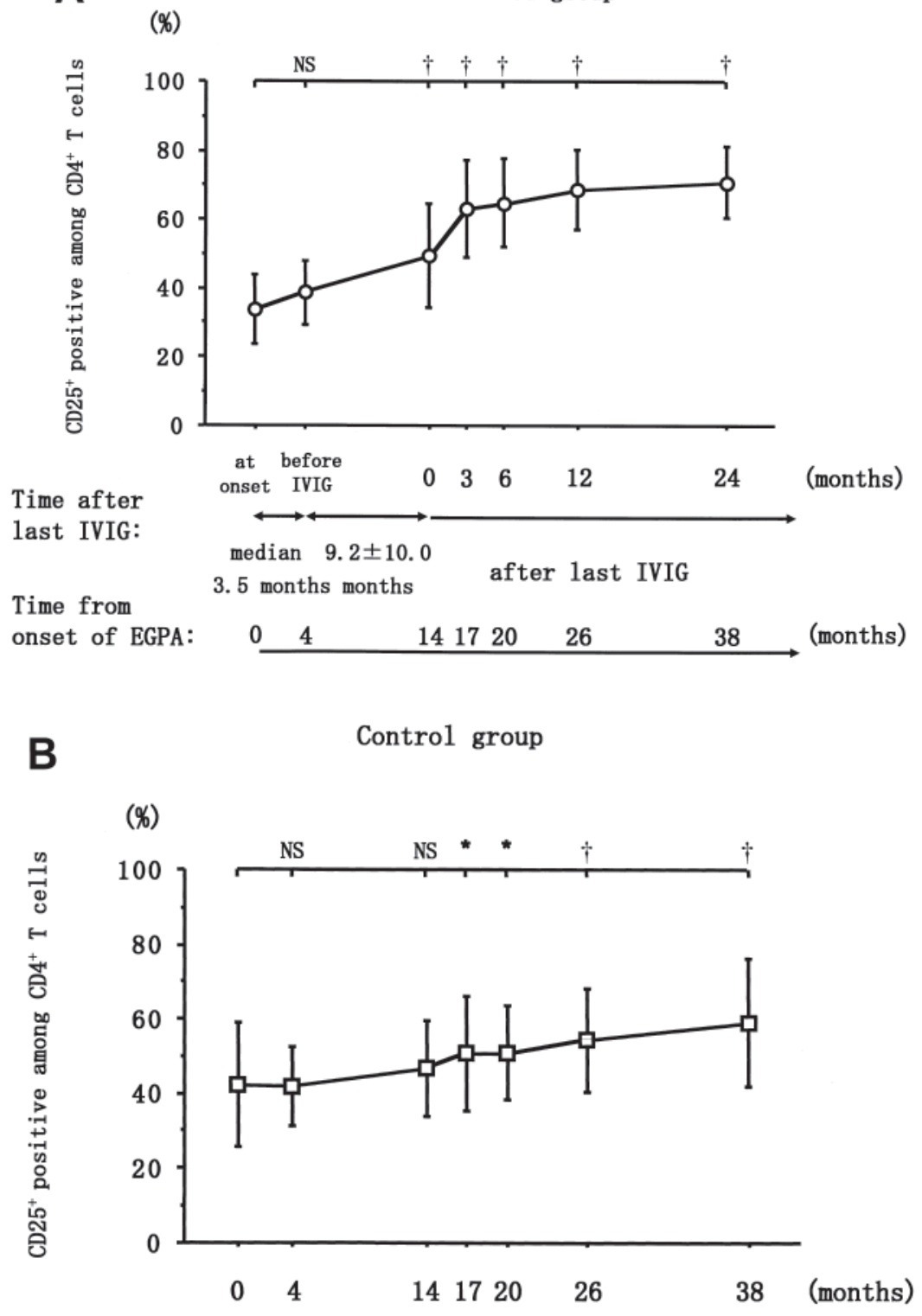

Time from onset of EGPA

Figure 2. Time course of the percentage of CD25+ among CD4+ T cells in white blood cells of patients with EGPA who were treated with IVIG and those not treated with IVIG. A. Circles represent data for patients with EGPA who were treated with IVIG in combination with CS, immunosuppressant, or both. B. Squares represent data for patients with EGPA treated with CS, immunosuppressant, or both, but not with IVIG. Lines across the upper part indicate comparisons relative to onset of the study for each group. Onset and later timepoints within each group were compared using repeated measures ANOVA. Error bars represent mean \pm SD. Differences between patient groups were evaluated by Mann-Whitney U test. ${ }^{\dagger} \mathrm{p}<0.01 ;{ }^{*} \mathrm{p}<0.05$; NS: not significant; CS: corticosteroids; IVIG: intravenous immunoglobulin; EGPA: eosinophilic granulomatosis with polyangiitis.

among CD4+ T cells correlated with the time from initial treatment to the last IVIG (Figure 3). In both the IVIG-treated and control groups, the percentage of FOXP3+ among $\mathrm{CD} 4+\mathrm{T}$ cells and the percentage of IL-10 produced by
$\mathrm{CD} 25+\mathrm{CD} 4+\mathrm{T}$ cells at onset and at remission correlated significantly with the percentage of CD25+ among CD4+ T cells (Figure 4A and 4B, respectively). For IVIG-treated patients who went into remission, the numbers of WBC, 


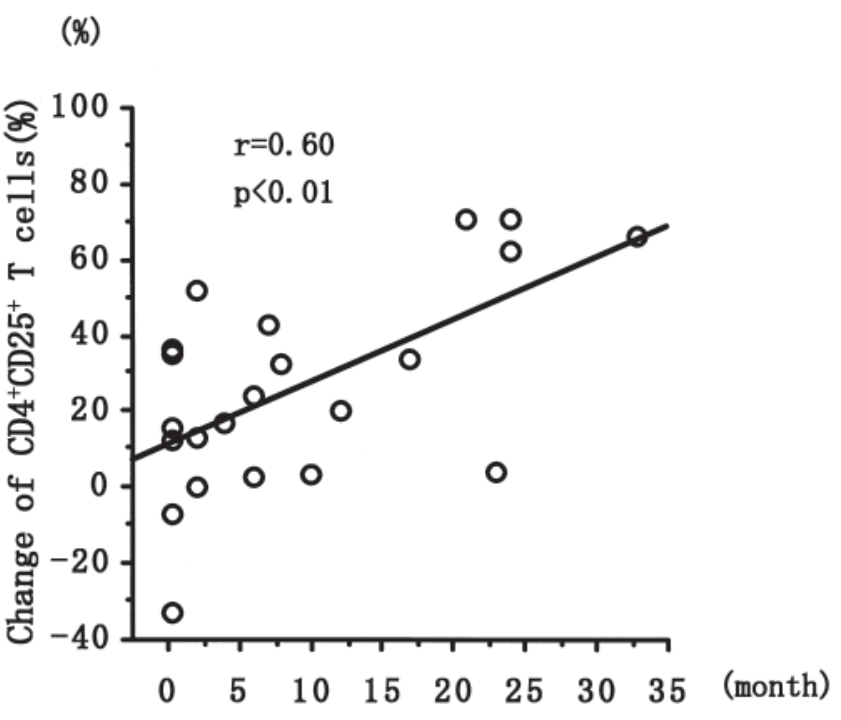

Time from initial IVIG to last IVIG

Figure 3. Relation between change of $\mathrm{CD} 4+\mathrm{CD} 25+\mathrm{T}$ cells and the time from initial IVIG to last IVIG treatment. Correlation coefficients (r) were obtained by Spearman's rank correlation test. IVIG: intravenous immunoglobulin.

eosinophils, and the percentage of IL-10-producing CD4+CD25+ T cells did not differ between the 2 remitting groups, but the percentages of CD25+ among CD4+ T cells and FOXP3+ among CD4+ T cells increased compared to those in the control group $(\mathrm{p}<0.05$; Table 4$)$. At the clinical level, the percentage of patients using immunosuppressants at remission did not differ significantly between the 2 groups; however, the dose of PSL was significantly lower $(\mathrm{p}<0.05)$ in patients treated with IVIG (Table 4).

\section{DISCUSSION}

The patient population we studied had severe EGPA clinical symptoms, as indicated by the high percentage of patients with severe cardiac or GI tract involvement, or severe multiple polyneuropathy. We previously reported that IVIG therapy improved mononeuritis multiplex or heart failure in 14 of 15 patients with EGPA who did not respond to the combination therapy of CS and CYC $\mathrm{C}^{5}$. The mean number of treatments with IVIG was $2.6 \pm 2.1$, with 7 of 22 patients $(31.8 \%)$ receiving only 1 IVIG treatment. Nevertheless, even in patients with EGPA who received only a single treatment with IVIG, CD4+CD25+ Treg cells increased more than in those not receiving IVIG and remained elevated for an extended period. We reported previously that patients with EGPA who are in remission have increased expression of indoleamine 2,3-dioxygenase on CD14+ monocytes, increased frequency of Treg cells, and decreased frequency of Th17 cells ${ }^{17}$. We also reported that an increase in the percentage of CD4+CD25+ T cells correlated with improved vasculitic symptoms ${ }^{7}$. Thus we suggested that IVIG treatment may increase indoleamine 2,3-dioxygenase activity, which helps restore impaired Treg cells and decreases the frequency of Th17 cells. It is reported that IVIG, especially $\mathrm{F}\left(\mathrm{ab}^{\prime}\right)_{2}$, inhibited the differentiation or amplification and function of Th17 cells and enhanced FOXP3-positive Treg

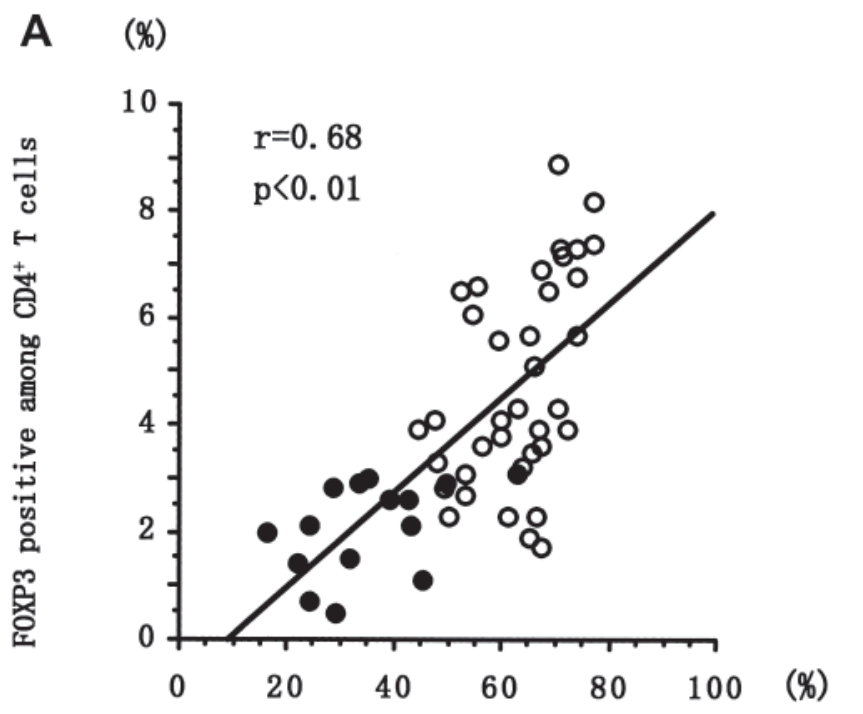

CD25 positive among $\mathrm{CD}^{+} \mathrm{T}$ cells
B

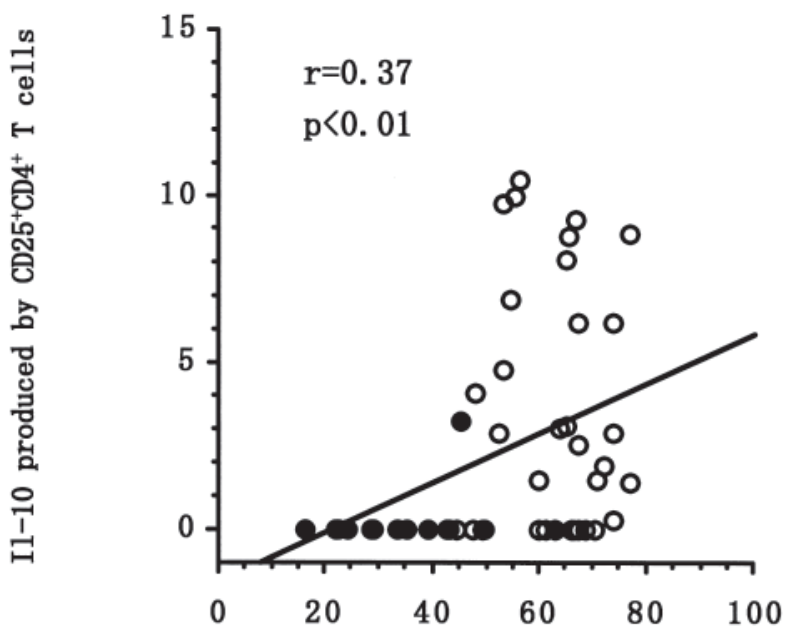

(\%)

CD25 positive among $\mathrm{CD}^{+} \mathrm{T}$ cells

Figure 4. Correlation between percentage of CD25+ among CD4+ T cells and FOXP3+ among CD4+ T cells (A) and interleukin 10 produced by CD25+CD4+ T cells (B). Closed circles represent data for patients with EGPA at onset and open circles are for patients in remission from EGPA, some of whom were treated with IVIG. Assays were performed $8.9 \pm 6.5$ years (mean \pm SD) after onset of EGPA. Correlation coefficients (r) were obtained by Spearman's rank correlation test. IVIG: intravenous immunoglobulin; EGPA: eosinophilic granulomatosis with polyangiitis.

Personal non-commercial use only. The Journal of Rheumatology Copyright $@$ 2012 . All rights reserved. 
cells $^{12}$. We hypothesized that an increase in Treg cells in peripheral blood may improve blood circulation in impaired organs.

Our data suggest that IVIG therapy may be useful for improving the prognosis of EGPA patients with severe organ involvement through prevention of side effects due to reduced CS intake, prevention of muscle atrophy, or maintenance of cardiac function.

\section{REFERENCES}

1. Churg J, Strauss L. Allergic granulomatosis, allergic angiitis, and periarteritis nodosa. Am J Pathol 1951;27:277-301.

2. Guillevin L, Lhote F, Gayraud M, Cohen P, Jarrousse B, Lortholary $\mathrm{O}$, et al. Prognostic factors in polyarteritis nodosa and Churg-Strauss syndrome: A prospective study in 342 patients. Medicine 1996;75:17-28.

3. Richter C, Schnabel A, Csernok E, De Groot K, Reinhold-Keller E, Gross WL. Treatment of anti-neutrophil cytoplasmic antibody (ANCA)-associated systemic vasculitis with high-dose intravenous immunoglobulin. Clin Exp Immunol 1995;101:2-7.

4. Renaldini E, Spandrio S, Cerudelli A, Affatato A, Balestrieri GP. Cardiac involvement in Churg-Strauss syndrome: A follow-up of three cases. Eur Heart J 1993;14:1712-6.

5. Tsurikisawa N, Taniguchi T, Saito H, Himeno H, Ishibashi A, Suzuki S, et al. Treatment of Churg-Strauss syndrome with high-dose intravenous immunoglobulin. Ann Allerg Asthma Immunol 2004;92:80-7.

6. Roncarolo MG, Battaglia M. Regulatory T-cell immunotherapy for tolerance to self antigens and alloantigens in humans. Nat Rev Immunol 2007;7:585-98.

7. Tsurikisawa N, Saito H, Tsuburai T, Oshikata C, Ono E, Mitomi H, et al. Differences in regulatory $\mathrm{T}$ cells between Churg-Strauss syndrome and chronic eosinophilic pneumonia with asthma. J Allergy Clin Immunol 2008;122:610-6.
8. Kazatchkine MD, Kaveri SV. Immunomodulation of autoimmune and inflammatory disease with intravenous immune globulin. N Engl J Med 2001;345:747-55.

9. Maddur MS, Othy S, Hegde P, Vani J, Lacroix-Desmazes S, Bayry $\mathrm{J}$, et al. Immunomodulation by intravenous immunoglobulin: Role of regulatory T cells. J Clin Immunol 2010;Suppl 1:S4-8.

10. Kessel A, Ammuri H, Peri R, Pavlotzky ER, Blank M, Shoenfeld Y, et al. Intravenous immunoglobulin therapy affects T regulatory cells by increasing their suppressive function. J Immunol 2007;179:5571-5.

11. De Groot AS, Moise L, McMurry JA, Wambre E, Van Overtvelt L, Moingeon $\mathrm{P}$, et al. Activation of natural regulatory $\mathrm{T}$ cells by $\mathrm{IgG}$ Fc-derived peptide "Tregitopes". Blood 2008;112:3303-11.

12. Maddur MS, Vani J, Hegde P, Lacroix-Desmazes S, Kaveri SV, Bayry J. Inhibition of differentiation, amplification, and function of human TH17 cells by intravenous immunoglobulin. J Allergy Clin Immunol 2011;127:823-30.

13. Ephrem A, Chamat S, Miquel C, Fisson S, Mouthon L, Caligiuri G, et al. Expansion of $\mathrm{CD} 4+\mathrm{CD} 25+$ regulatory $\mathrm{T}$ cells by intravenous immunoglobulin: A critical factor in controlling experimental autoimmune encephalomyelitis. Blood 2008;111:715-22.

14. Masi AT, Hunder GG, Lie JT, Michel BA, Bloch DA, Arend WP, et al. The American College of Rheumatology 1990 criteria for the classification of Churg-Strauss syndrome (allergic granulomatosis and angiitis). Arthritis Rheum 1990;33:1094-100.

15. Abdulahad WH, Stegeman CA, van der Geld YM, van der Meer BD, Limburg PC, Kallenberg CGM. Functional defect of circulating regulatory CD4+ T cells in patients with Wegener's granulomatosis in remission. Arthritis Rheum 2007;56:2080-91.

16. Picker LJ, Singh MK, Zdraveski Z, Treer JR, Waldrop SL, Bergstresser PR, et al. Direct demonstration of cytokine synthesis heterogeneity among human memory/effector $\mathrm{T}$ cells by flow cytometry. Blood 1995;86:1408-19.

17. Saito H, Tsurikisawa N, Tsuburai T, Oshikata C, Akiyama K. The proportion of regulatory $\mathrm{T}$ cells in the peripheral blood reflects the relapse or remission status of patients with Churg-Strauss syndrome. Int Arch Allergy Immunol 2011;155:46-52. 